Journal of Patient-Centered

Volume 3

Issue 4 -- Cardiovascular Aging

Article 22

$11-11-2016$

\title{
Evaluation of Preoperative Anemia and Transfusion Requirements in Adult Liver Transplant Recipients
}

\author{
Parissa M.N. Moghimi \\ Erika A. Aldag \\ Rachel Pedersen \\ Ajay Sahajpal \\ Jacob N. Clendenon \\ Vikraman Gunabushanam \\ Mehraboon S. Irani \\ David J. Kramer
}

Follow this and additional works at: https://aah.org/jpcrr

Part of the Critical Care Commons, Digestive System Diseases Commons, Fluids and Secretions Commons, and the Hepatology Commons

\section{Recommended Citation}

Moghimi PM, Aldag EA, Pedersen R, Sahajpal A, Clendenon JN, Gunabushanam V, Irani MS, Kramer DJ. Evaluation of preoperative anemia and transfusion requirements in adult liver transplant recipients. J

Patient Cent Res Rev. 2016;3:241-2.

Published quarterly by Midwest-based health system Advocate Aurora Health and indexed in PubMed Central, the Journal of Patient-Centered Research and Reviews (JPCRR) is an open access, peer-reviewed medical journal focused on disseminating scholarly works devoted to improving patient-centered care practices, health outcomes, and the patient experience. 
$\mathrm{CRC}$ death, making early $\mathrm{CRC}$ screening an imperative. While the Wisconsin Collaborative for Healthcare Quality ranks Aurora Health Care as eighth out of 20 systems in Wisconsin (77.6\% from 2014 Q3 to 2015 Q2), local data analysis identified age as the largest disparity gap. Analyzing local population REAL/gender data provides key insights to support initiatives to reduce health disparity gaps and further progress toward achieving the Triple Aim for health care.

\section{WISE-Family Medicine: A Statewide Faculty Development Collaborative}

Deborah Simpson, Kjersti Knox, Anne Getzin, John R. Brill, Melissa M. Stiles, Jeffrey A. Morzinski

Departments of Academic Affairs and Family Medicine, Aurora UW Medical Group; Department of Family Medicine and Community Health, University of Wisconsin School of Medicine and Public Health; Department of Family and Community Medicine, Medical College of Wisconsin

Background: In many states, family medicine residencies and medical schools compete clinically for patients, educationally for trainees and, more recently, for community preceptors (CPs). As Wisconsin's medical schools and health care systems have expanded their geographic footprints, our CPs now teach trainees from competing institutions. Yet residency and medical student accrediting bodies require faculty and preceptor development.

Purpose: To evaluate the impact of a statewide collaborative of family medicine educators on meeting faculty development needs of our CPs and collaborative members.

Methods: Faculty development leaders representing the three largest family medicine residency training sponsors in the state created the Wisconsin Institute of Scholars \& Educators in Family Medicine (WISE-FM). This statewide collaborative of family medicine educators is comprised of 3 to 4 representatives per sponsor — both junior and senior educators to further support their development as faculty - committed to developing common preceptor clinical teaching tools. Through online discussions and half-day WISE-FM meetings, WISEFM participants identified preceptor development needs and designed highly regarded clinical teacher infographics for these priority topics. These tools are available for use statewide, providing CPs with a consistent teaching approach. To determine infographic value, a brief ( $<5$ items) parallel form survey was distributed to and voluntarily completed by: 1) CPs who received the infographics, and 2) WISE-FM participants. Item results on a 5 -point Likert scale ( $5=$ strongly agree, $1=$ strongly disagree) were analyzed using descriptive statistics.

Results: Forty-two CP infographics recipients and the 11 WISEFM participants completed the evaluations. Results revealed that faculty development infographics were a time-efficient (CP: 4.1, WISE-FM: 4.2) and effective way (CP: 4.0, WISEFM: 4.2) to enrich skills as clinical teachers. Both groups intend to or have incorporated the infographics into their own teaching (CP: 4.2, WISE-FM: 4.2). WISE-FM respondents strongly agreed (4.6) that the overall "returns" from participating were worth their investments (time, effort).

Conclusion: The WISE-FM provides a statewide faculty development model that can be adopted by others to meet accreditation requirements for CP teaching skill development through shared authoring of $\mathrm{CP}$ development resources while concurrently advancing the development of WISE-FM participants.

\section{Evaluation of Preoperative Anemia and Transfusion Requirements in Adult Liver Transplant Recipients}

\section{Parissa M.N. Moghimi, Erika A. Aldag, Rachel Pedersen, Ajay Sahajpal, Jacob N. Clendenon, Vikraman Gunabushanam, Mehraboon S. Irani, David J. Kramer}

Departments of Pharmacy, Abdominal Transplant, Transfusion Services and Critical Care Medicine, Aurora Health Care

Background: Liver transplantation is often associated with massive blood loss due to surgical complexity and the hemostatic abnormalities of end-stage liver disease. Blood transfusions have been associated with increased risk of infection, multiorgan dysfunction, graft loss and mortality.

Purpose: To determine for liver transplantation whether correlation exists between preoperative anemia and transfusion requirements, length of stay or incidence of postoperative infection.

Methods: A retrospective review of liver transplantations from Jan. 1, 2012, to June 30, 2015, was conducted. Packed red blood cell (PRBC), fresh frozen plasma (FFP), platelet and cryoprecipitate units were collected preoperatively, intraoperatively and within the first 48 hours postoperatively. Cox proportional hazards model was used to model the outcome of infection. Linear regression was used to model the outcomes of postoperative length of stay and blood use.

Results: Of the 112 patients, mean age was 56 years, mean Model for End-Stage Liver Disease score was 27 and mean preoperative hemoglobin was $10.5 \mathrm{~g} / \mathrm{dL}$. Lower preoperative hemoglobin was significantly associated with increased preoperative $\mathrm{PRBC}$, platelet and cryoprecipitate use $(\mathrm{P}<0.04)$ as well as increased intraoperative PRBC, FFP, platelet and cryoprecipitate use $(\mathrm{P}<0.0001)$. Preoperative PRBC, FFP, and platelets as well as intraoperative PRBCs were associated with longer length of stay $(\mathrm{P}<0.045)$. Each $\mathrm{g} / \mathrm{dL}$ decrease in preoperative hemoglobin was associated with a $26 \%$ increased risk of infection in univariate models (hazard ratio $[\mathrm{HR}]$ : 1.26, $\mathrm{P}=0.01$ ). Longer length of stay and higher preoperative cryoprecipitate, intraoperative FFP and postoperative FFP also were associated with increased risk of infection. More units of preoperative cryoprecipitate (HR: $1.07, \mathrm{P}<0.01)$, fewer units of postoperative cryoprecipitate (HR: $0.19, \mathrm{P}<0.01$ ) and more units of postoperative FFP (HR: 1.75, $\mathrm{P}<0.01$ ) were associated with infection in multivariable stepwise selection.

Conclusion: Lower preoperative hemoglobin was associated with increased preoperative and intraoperative transfusion 
requirements as well as increased postoperative infection. More preoperative cryoprecipitate units, fewer postoperative cryoprecipitate units and more fresh frozen plasma units were independent predictors of infection.

\section{Effect of Code Status Handout on Resident Physician Comfort During the Admission Process}

Krystina Pischke, Jessica Schmid, Jessica J.F. Kram, Dennis J. Baumgardner

Department of Family Medicine, Aurora Health Care; Department of Family Medicine, Aurora UW Medical Group; Center for Urban Population Health

Background: Discussing code status can be a difficult part of the admission process, especially for residents. There have been various research studies looking at interventions to improve end-of-life discussions. However, these studies have focused on well-acquainted physicians and patients. With increasing use of hospitalists for inpatient care, there is increased need for improving code status discussions at admission.

Purpose: To determine if an easy-to-use handout would improve resident comfort with the code status discussion.

Methods: Following a literature search on how to discuss advance directives and end-of-life care, a code status handout was developed. The handout, written at fifth-grade reading level, was edited by attending physicians who oversaw the Adult Medicine Teaching Service (AMTS) at Aurora St. Luke's Medical Center, and used for patient admissions to AMTS by PGY1-3 residents from July 2015 to December 2015. A pre- and postintervention survey was emailed to residents before and after the start of their inpatient rotation, respectively. A predetermined script — read to residents on the first day of their rotation - discussed the handout, goals of the study and surveys. Paired t-tests were used to compare pre- and postintervention survey responses.

Results: Across respondents ( $\mathrm{N}=39)$, the majority were PGY1 $(63.2 \%)$ with prior personal experience explaining code status to patients $(73.7 \%)$. Pre- and postintervention surveys did not identify a difference in physician comfort level when explaining code status, even when compared to year in residency. On the postintervention survey, residents identified that the code status handout better informed patients $(73.0 \%)$, was easy to use $(75.0 \%)$ and that they would continue to use the handout to explain code status (78.4\%). Regarding "What would you change?" residents identified that the handout should be shorter (34.2\%).

Conclusion: Use of the handout did not show significant improvements to resident comfort in this small pilot. While residents identified that they would use the handout again, several remarked that the handout was too long for them or patients to read. Given that the handout was one page and in patient-friendly language, it is concerning that residents have such limited time for code status discussions. Future quality improvement studies should be conducted to standardize the code status discussion. Doing so will ensure that every patient is being properly educated on this important topic.
Evaluation of Patient Opinions and Experiences With Electronic Cigarettes at a Family Medicine Residency Clinic

Ima D. Tanner, Breana C. Cummens, Jessica J.F. Kram, Dennis J. Baumgardner

Department of Family Medicine, Aurora Health Care; Department of Family Medicine, Aurora UW Medical Group; Center for Urban Population Health

Background: Since 2003, electronic cigarettes (e-cigs) have grown in popularity. E-cigs are often marketed as a safer, healthier alternative to smoking traditional cigarettes or as an aid for smoking cessation. However, the risks and benefits of e-cig use, as well as the beliefs that influence use or avoidance, are poorly understood.

Purpose: To assess our patient population's perception or beliefs as they relate to e-cig use.

Methods: A 13-question survey regarding nicotine and e-cig use was distributed to English-speaking adult patients at Aurora St. Luke's Family Practice Clinic from August 2015 to January 2016. Questions assessed patient demographics and smoking history as well as knowledge and opinions of e-cigs. Descriptive statistics were used to describe patient characteristics. Associations between patient characteristics and beliefs were analyzed using chi-squared tests and Fisher's exact test, as appropriate. Significance was associated with $\mathrm{P}<0.05$.

Results: Across respondents $(\mathrm{N}=100)$, patients were more likely to be female $(60 \%)$ and of age $45-54$ years. Patients either had heard about e-cigs through advertisements $(48.9 \%)$ or by word of mouth $(36.9 \%)$. Many believed that e-cigs could help others quit smoking (47.6\%) and were a healthier smoking option over regular tobacco $(47.5 \%)$. Only $21.7 \%$ of patients had ever tried e-cigs. Age, sex and race/ethnicity were not associated with trying e-cigs. Those who identified as ever-smokers were more likely to have tried e-cigs than never-smokers $(\mathrm{P}=0.044)$. Additionally, current smokers were even more likely to have tried e-cigs than former or never smokers $(\mathrm{P}=0.017)$. Smoking status was not associated with education and race/ethnicity. Views regarding cost and whether e-cigs were a good choice for cessation also were not associated with smoking status.

Conclusion: Smoking status significantly affects whether a patient has tried e-cigs, with current smokers being most likely to have tried them. Demographic characteristics were not associated with use or opinions of e-cigs. Future studies should be done to assess use and attitudes in other clinic settings as well as use within our adolescent patient populations. 